\title{
Distinct IRAK4 Expression in Normal and B-CLL Lymphocytes
} Halina Antosz ${ }^{* 1}$, Joanna Sajewicz' ${ }^{1}$, Barbara Marzec-Kotarska' ${ }^{1}$, Dorota Choroszynska ${ }^{1}$, Iwona Hus ${ }^{2}$, Malgorzata Jargiello-Baszak ${ }^{3}$ and
Jacek Baszak ${ }^{3}$

${ }^{1}$ Department of Clinical Genetics, Medical University of Lublin, Lublin, Poland

${ }^{2}$ Department of Clinical Immunology, Medical University of Lublin, Lublin, Poland

${ }^{3}$ Department of Cardiology, Medical University of Lublin, Lublin, Poland

\begin{abstract}
Toll-like receptors (TLR) signaling plays an important role in the B cell biology. It induces the maturation, proliferation and antibody production in response to pathogen recognition. Interleukin-1 Receptor-associated Kinase-4 (IRAK-4) is TLR downstream molecule which is of strategic importance in starting a cascade of NF-kappaB (Nuclear factor-kappaB) and MAPK (Mitogen-activated protein kinase) intracellular signaling pathways. The aim of the study was to identify the differences in IRAK-4 expression in normal and chronic lymphocytic leukemia (CLL) lymphocytes. We have also studied the IRAK-4 expression alteration upon TLR2/4 ligand stimulation in leukemic and normal B cells.
\end{abstract}

We carried out Real-Time PCR and Western blot analysis of IRAK4 mRNA (RQ) and protein expression. The study were performed on the isolated CD19+ normal $B$ lymphocytes and CLL cells (CD5+CD19+) before and 30 min after (Lipopolysaccharide) LPS and (Staphylococcus aureus strain Cowan I) SAC stimulation.

IRAK-4 mRNA expression was significantly higher in normal CD19+ lymphocytes as compared to leukemic $\mathrm{CD}^{+} \mathrm{CD} 19^{+}$subpopulation ( $R Q$ median 0.90 vs $0.54 ; \mathrm{p}=0.012$ ). In normal lymphocytes, LPS and $\mathrm{SAC}$ treatment led to significant IRAK-4 down-regulation both at mRNA (RQ median 0.90 vs 0.53 vs $0.40 ; p=0.03, p=0.01$ ) and protein level, whereas generally there were no significant changes in IRAK-4 expression neither on mRNA nor protein level.

No trend or significant differences in IRAK-4 expression in leukemic lymphocytes after LPS and SAC stimulation may imply the presence of alleged defect of immune tolerance in CLL.

\section{Keywords: IRAK-4; TLR; CLL; LPS; SAC}

\section{Introduction}

The human body defense against pathogens occurs through integration of innate and adaptive immunity. Both types of immune function are mediated by intrinsic cellular and molecular interactions $[1,2]$. Various cell types endued with pattern recognition receptors (PRRs), including Toll-like receptors (TLRs), are involved in innate immune system action in mammals. TLRs perform constant supervision of the environment in search of pathogens, while distinguishing their own antigens from the foreign ones. Adaptive immunity, which is evolutionary younger, use of antigen-specific receptors on the surface of $\mathrm{B}$ and $\mathrm{T}$ lymphocytes (BCR, TCR) in response to specific and changing antigens [3]. B cells play the main role in this context. They produce antibodies against these specific antigens, function as antigen presenting cells for $\mathrm{T}$ cells, produce cytokines $[4,5]$. Lymphocytes $\mathrm{T}$ show TLRs receptors expression, which are typical for innate immunity.

In humans, ten different TLRs have been identified. Some of them are localized on the cell surface (TLR1, 2,4,5,6,10) while the other ones, on the endosomes (TLR3,7,8,9) They consist of transmembrane domain with leucine-rich repeats (LRRs), and cytoplasmic TIR domain (Toll/interleukin-1 resistance protein) [6,7]. TIR domains confer specificity to different TLRs enabling each of the receptors (via TIR-TIR homotypic interactions), communication with the signaling adaptor proteins [8-10]. Ligand, binding to the receptor, generally induces receptor dimerization, recruitment of adaptor molecules and activation of kinase cascade series. In the case of lipopolysaccharide (LPS) receptor TLR4 or the lipoprotein receptor TLR2, the adaptor molecules MyD88 (myeloid differentiation factor 88) and TIRAP/ MAL (TIR-domain-containing adaptor protein, also called MyD88 adaptor-like) are recruited to activate nuclear factor-kappaB (NF-kBtranscription factor) and induce proinflammatory cytokines, such as
IL-1 (interleukin-1), IL-6 (interleukin-6) and TNF (tumor necrosis factor) [11].

Unlike TIRAP/Mal, MyD88 has an N-terminal death domain responsible for interaction with IRAK kinases family members [12] After LPS stimulation, IRAK1 (Interleukin-1 Receptor-associated Kinase-1) is recruited to the TLR4 receptor complex, where it undergoes phosphorylation in its threonine key locations by serine/threonine IRAK4 kinases. IRAK4 is of strategic importance in starting a cascade of NF- $\mathrm{KB}$ and MAPK intracellular signaling pathways. Based on mutagenesis studies, it was demonstrated that the active kinase IRAK4 is absolutely essential for the activation of NF- $\mathrm{\kappa B}$ [13]. Therefore, IRAK- 4 is considered to be a central mediator in TIR signaling innate immunity [14] and has been proposed to be the only true kinase of the IRAK family [15]. Studies on mice and clinical observations of IRAK-4 deficient patients showed that the absence/deficiency of IRAK-4 results in severe immune deficiency [16,17].

Severe immune system disorders, i.e. hypogammaglobulinemia, impaired immunoglobulin class switching are typical features of patients with chronic lymphocytic leukemia (CLL) [18]. This makes

*Corresponding author: Halina Antosz, Department of Clinical Genetics, Medical University of Lublin, 11 Radziwillowska Street, 20-950 Lublin, Poland, Tel/Fax: (0048) 81 5288408; E-mail: hagenetyka@wp.pl

Received December 09, 2013; Accepted March 19, 2014; Published March 21, 2014

Citation: Antosz H, Sajewicz J, Marzec-Kotarska B, Choroszynska D, Hus I, et al. (2014) Distinct IRAK4 Expression in Normal and B-CLL Lymphocytes. J Cyto Histol 5: 228. doi:10.4172/2157-7099.1000228

Copyright: ( 2014 Antosz H, et al. This is an open-access article distributed under the terms of the Creative Commons Attribution License, which permits unrestricted use, distribution, and reproduction in any medium, provided the original author and source are credited. 
patients with CLL very susceptible to infections, which significantly contribute to their morbidity and mortality.

Chronic lymphocytic leukemia is a monoclonal disorder characterized by a progressive accumulation of $\mathrm{CD}^{+} \mathrm{CD} 19^{+} \mathrm{B}$ cells, functionally incompetent, frequently associated by the other immune disturbances. Low expression of BCR (B-cell receptor) is the hallmark of the CLL lymphocytes [19]. Besides antibody production, normal B cells have important antigen presenting functions [20]. It has been shown [21] that the activation of human naive $B$ cells requires a combination of three signals: 1/BCR triggering, 2/cognate T cell help, and 3/ TLR stimulation.

It seems that there is no harmony between these signals in CLL. BCR signaling may be defective, which is related to small numbers of BCR, non-functional BCR assembly $[19,22]$ and mutations in accessory proteins [23]. Consequently, it abolishes the ability of antigen presentation by CLL cells [24]. In patients with CLL, many T cells acquired defect were also found, such as: increase of $\mathrm{T}$ cell number, reversal of the CD4: CD8 ratio, alterations in T-cell cytoskeleton formation and vesicle transportation and production of cytokine inhibitors, IL-6, IL-10, TNF (Tumor necrosis factor) and TGF-beta (Tumor Growth Factor beta) [25-29]. Finally, CLL is associated with the impairment of the innate immune system [30,31].

TLR stimulation triggers the activation of signals that eventually turn into a transcription of specific genes. Therefore, the defect in any of the signaling pathway links concerning activation signal transmission from TLRs may underlay the cause of immune failure in CLL.

In this study, we compared the expression of IRAK4 on mRNA and protein level in $\mathrm{CD}^{+} \mathrm{CD} 19^{+}$leukemic B lymphocytes and normal $\mathrm{CD} 19^{+} \mathrm{B}$ cells from age adjusted healthy donors. Simultaneously, we assessed the expression of IRAK4 in both subpopulations upon LPS (lipopolysaccharide Escherichia coli) and SAC (Staphylococcus aureus Cowan strain I) stimulation.

\section{Methods}

\section{Patients}

The study was approved by the Ethics Committee at the Medical University of Lublin. Peripheral blood samples were obtained from 35 patients diagnosed with chronic lymphocytic leukemia (CLL) (21 male and 14 female; median age - 63 range: 51-79 years) in Haematooncology and Bone Marrow Transplantation Department, Medical University of Lublin, Poland. Project of the study was accepted by Bioethical Committee of Medical University in Lublin (number KE-0254/108/2011). Written informed consent was obtained from all the patients. The diagnoses of CLL based on the standard clinical, morphological and immunophenotypic criteria [32]. All the patients were previously untreated.

The total lymphocyte count ranged from 11.23 to $652 \times 10^{9} / \mathrm{L}$. The disease stage was defined according to the Rai classification [33]. Patients were graded as follows: stage 0 (6 cases), stage I (8 cases), stage II ( 6 cases) stage III ( 9 cases), and stage IV ( 6 cases). The control group included 20 healthy volunteers, 8 females and 12 males in the age adjusted to the study group (median - 61, range 50-77).

Peripheral blood mononuclear cells were isolated by density gradient centrifugation with Lymphoprep (Nycomed, Pharma AS, Norway) using the standard Böyum method [34].

\section{Cell cultures and stimulation}

Normal peripheral blood lymphocytes and CLL cells were cultured in RPMI-1640 medium (Gibco) containing FCS (10\%) (Fetal Calf Serum), HEPES (10 mM), glutamine $2 \mathrm{mM}$, streptomycin $(100 \mu \mathrm{g} / \mathrm{ml})$, penicillin $(100 \mathrm{U} / \mathrm{ml})$ (Polfa, Poland) on culture plates $\left(10^{6} \mathrm{cell} / \mathrm{ml}\right)$ (Corning Inc, USA) at $37^{\circ} \mathrm{C}$ in humidified $5 \% \mathrm{CO}_{2}$ atmosphere for 30 minutes. CLL cells and normal lymphocytes, at the concentration $1 \times 10^{6}$ cells per ml media, were stimulated with purified TLR agonists: $10 \mu \mathrm{g} / \mathrm{ml}$ LPS (Lipopolysaccharide from Escherichia coli, Sigma) or formalinised SAC (Staphylococcus aureus strain Cowan I) in the insoluble form, $1.2 \times 10^{6}$ microorganisms $/ \mathrm{ml}$. Normal $\mathrm{CD} 19^{+}$subpopulations were isolated from half hour cultured normal lymphocytes using magnetic columns (Miltenyi Biotech, Bergisch Gladbach, Germany).

\section{Flow cytometry analysis}

Immunophenotyping was performed by flow cytometry (FACSCalibur, Becton Dickinson Immunocytometry System) using commercial mouse monoclonal antibodies (anti-human CD19/ PE-Cy5, anti-human CD5/FITC, Becton Dickinson) and respective immunoglobulin isotype controls. Cells were stained for surface markers according to the supplier's instructions. The cells were gated according to their FSC (forward scatter) and SSC (side scatter). Analyses were carried out using Cell QUEST Software (Becton Dickinson) on gated lymphocytes.

\section{Real-Time PCR}

The expressions of IRAK4 in unstimulated, LPS- and SAC-stimulated B-CLL samples and normal CD19+ lymphocytes were performed using RT-PCR. Total RNA was extracted by TRI Reagent (Sigma) using the Chomczynski method [35], and was reverse transcribed into cDNA with the High-Capacity cDNA Reverse Transcription Kit (Applied Biosystems) according to the supplier's instructions. Real-Time PCR was carried out using the 7300 Real-Time System (Applied Biosystems) at $50^{\circ} \mathrm{C}$ for $2 \mathrm{~min}$ and at $95^{\circ} \mathrm{C}$ for $10 \mathrm{~min}$, followed by 40 cycles at $95^{\circ} \mathrm{C}$ for $15 \mathrm{~s}$ and at $60^{\circ} \mathrm{C}$ for $1 \mathrm{~min}$. The probe for GAPDH (Hs99999905_m1) was commercially purchased (Applied Biosystems), so was the primer for IRAK4 (Hs00928779_m1). The expression of GAPDH was used for normalization of Real-Time reaction. The assays were performed in triplicate, the average mean was calculated, and the expression level of IRAK4 (RQ) was described as $2^{-\Delta \Delta C t}$.

\section{Western Blot analysis}

Western blot analysis was performed to evaluate the protein level of IRAK4. Unstimulated, LPS- and SAC-treated B-CLL and normal CD19+ $B$ lymphocytes were subjected for protein isolation. $\beta$-actin was used as an internal loading control. Briefly, $10 \times 10^{6}$ cells were harvested in the presence of a protease inhibitor cocktail (Sigma-Aldrich) in CelLytic MT Mammalian Tissue Lysis/Extraction Reagent (Sigma-Aldrich). The mixture was homogenized; cell lysates were clarified of cell debris by centrifugation at $14000 \mathrm{xg}$ for $15 \mathrm{~min}$ at $4^{\circ} \mathrm{C}$. The supernatant was collected, protein concentration was determined using NanoDrop 2000 (Thermo Scientific). The samples were mixed in NuPAGE LDS Sample Buffer 4x (Invitrogen), Nu PAGE Reducing Agent 10x (Invitrogen), Deionized Water (Sigma-Aldrich), denatured at $70^{\circ} \mathrm{C}$ for $10 \mathrm{~min}$, chilled on ice and immediately subjected to electrophoresis. Equal amounts of proteins $(20 \mu \mathrm{g})$ were subjected to a $10 \%$ polyacrylamide gel (SDS-PAGE, Invitrogen) and electrophoresed for $60 \mathrm{~min}, 150 \mathrm{~V}$ (XCell SureLock, Invitrogen). Then proteins were dry transferred using iBlot Gel Transfer System (Invitrogen) for $7 \mathrm{~min}, 20 \mathrm{~V}$ to PVDF membranes. Nonspecific binding was blocked with $3 \%$ nonfat milk in TBS (Tris 


\begin{tabular}{|c|c|c|}
\hline \multicolumn{2}{|c|}{ Cell Culture } & mRNA (RQ) IRAK-4 \\
\hline \multirow{3}{*}{ Normal B } & Unstimulate & 0,90 \\
\cline { 2 - 3 } & LPS- stimulated & 0,53 \\
\cline { 2 - 3 } & SAC-stimulated & 0,40 \\
\hline \multirow{2}{*}{ CLL } & Unstimulate & 0,54 \\
\cline { 2 - 3 } & LPS- stimulated & 0,50 \\
\cline { 2 - 3 } & SAC-stimulated & 0,55 \\
\hline
\end{tabular}

Table 1: IRAK-4 mRNA (RQ) expression in unstimulated, LPS- and SAC-stimulated normal $\mathrm{CD} 19^{+}$and $\mathrm{B}-\mathrm{CLL} \mathrm{CD} 5^{+} / \mathrm{CD} 19^{+}$lymphocytes (median values).
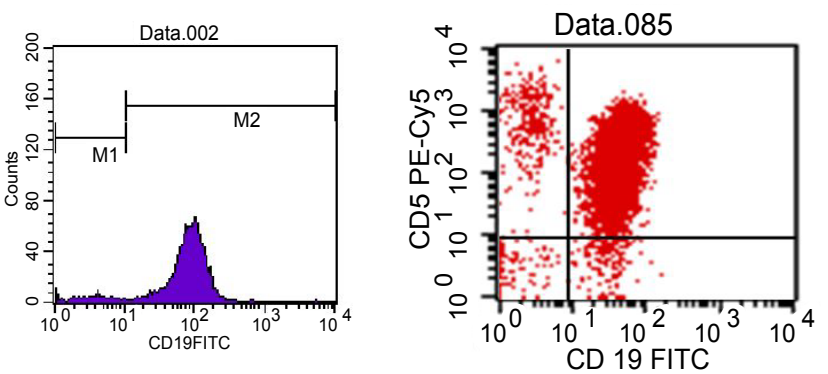

Figure 1: Normal B $\left(C D 19^{+}\right)(A)$ and CLL lymphocyte subpopulations (B).

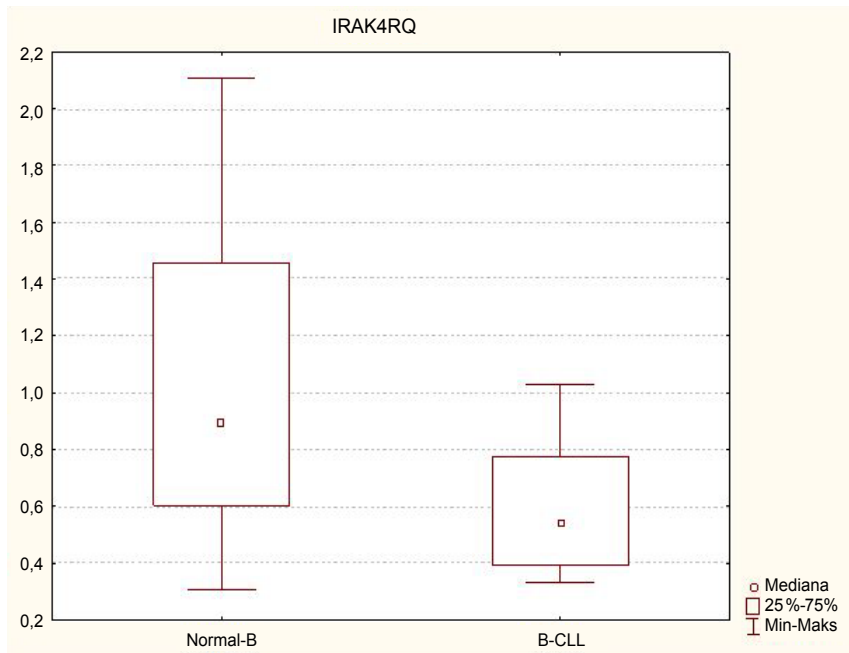

Figure 2: IRAK4 mRNA expression in unstimulated normal $C D 19^{+}$and CLL lymphocytes.

Buffered Saline with 3\% non-fat milk, $\mathrm{pH} 8$, Sigma-Aldrich) at room temperature for $1 \mathrm{~h}$. Membranes were then incubated with primary rabbit polyclonal anti-IRAK4 (1:500, 18600-17 US Biological), rabbit polyclonal anti-beta actin (1:2000, 8227-50 ABCAM), at $4^{\circ} \mathrm{C}$ over-night. The membranes were washed with TTBS (Tris Buffered Saline with 0,05\% Tween 20, Sigma-Aldrich) 3 times for 15 minutes, then incubated with secondary goat anti-rabbit immunoglobulin $\mathrm{G}$ (IgG)-horse radish peroxidase (HRP) (ABCAM) for $1 \mathrm{~h}$. The membranes were washed three times for $15 \mathrm{~min}$ with TBST. Bound antibody chemiluminescence was detected using chemiluminescence kit (SuperSignal West Pico Chemiluminescent Substrate, ThermoScientific) with Molecular Imager ChemiDoc XRS+ (BioRad). The optical density was determined using a scanning densitometer and analyzed using Quantity One software (Bio-Rad).

\section{Statistical analysis}

The obtained data were statistically analyzed using Statistica 8.0 software. Statistical significance was calculated by the Student's t-test. Statistical significance was considered at $\mathrm{p}<0.05$.

\section{Results and Discussion}

Under physiological conditions, TLRs act as costimulatory signal transmitters, which bridge the innate and adaptive immune response and provide a full activation of B cells. TLR-dependant signals may also be involved either in TLR induction of tolerance, or in supporting auto reactivity of B lymphocytes [36]. IRAK-4 plays a key role in the signaling of TLRs [37], although the regulatory mechanism remains unclear. Hatao et al., demonstrated that stimulation of TLR2, TLR4, TLR9 receptors, leads to IRAK-4 protein downregulation [38]. The available data on the expression and function of TLRs in CLL are limited and derive from small series of patients and the expression of proteins involved in signal transducing pathways in CLL was not analyzed. Therefore, the mechanism of immunodeficiency in CLL remains unclear.

Increasingly, antigen/antigens initiating simultaneous or various signals that act through receptors other than the BCR are suggested to influence the behavior of malignant clone and play a key role in the pathogenesis of CLL [39]. It does not preclude participation of TLRs in this process. Integration of TLR with antigen causes cell activation and induces the expression of proinflammatory cytokines, chemokines and defensin genes following maturation, proliferation and antibody production after pathogen recognition [40].

However, TLR responses must be tightly regulated, since uncontrolled production of cytokines may result in immunopathology. Thus, repeated or permanent stimulation of TLR can make the immune cells anergic to the same or different TLR ligands. This phenomenon, known as TLR tolerance, is well characterized in macrophages, particularly in the case of TLR4 and its LPS ligand [41-43]. The exact mechanism how the tolerance is induced is not clear, though downregulation of surface receptors, induction of transcription of negative regulators such as IRAK-M [44], SOCS- 1 and SHIP), the production of anti-inflammatory cytokines such as TGF- $\beta$ and IL-10 [45] were observed. It is not clear whether the response to TLR ligand binding on $\mathrm{B}$ cells is similarly regulated, and whether there are differences in the regulation between normal and CLL B cells.

In the present study, we analyzed the expression of IRAK4 in normal and CLL B lymphocytes. Real-Time PCR and Western blot analysis of IRAK4 mRNA (RQ) and protein expression were performed on the isolated CD19+ normal B lymphocytes and CLL cells $\left(\mathrm{CD}^{+} \mathrm{CD}^{+} 9^{+}\right)$before and $30 \mathrm{~min}$ after LPS and SAC stimulation. The mRNA expression of IRAK-4 is provided in (Table 1). The purity of normal $\mathrm{CD} 19^{+}$and $\mathrm{B}-\mathrm{CLL} \mathrm{CD} 19^{+} \mathrm{CD}^{+}$subpopulations was evaluated using flow cytometry. The normal B CD $19^{+}$lymphocyte count exceeded $94 \%( \pm 2,15)$, and CLL CD5 ${ }^{+} / \mathrm{CD}_{19}{ }^{+}$was $92 \%( \pm 1,82)$ (Figure $1 \mathrm{~A}$ and 1B). IRAK-4 mRNA expression was significantly higher $(\mathrm{p}=0.012)$ in normal CD19+ lymphocytes compared with $\mathrm{CD}^{+} \mathrm{CD} 19^{+} \mathrm{B}-\mathrm{CLL}$ subpopulation (0.90 vs 0.54 ) (Figure 2).

In the context of the above data, one can only speculate as to the cause of differential IRAK4 mRNA expression. Nomura et al. [42] showed that LPS stimulation of monocytes leads to the reduction of TLR4 expression. The minimal to undetectable TLR4 expression in CLL cells was observed [46]. It may be caused by chronic stimulation of CLL cells by unknown antigens, environmental factors and cytokines 


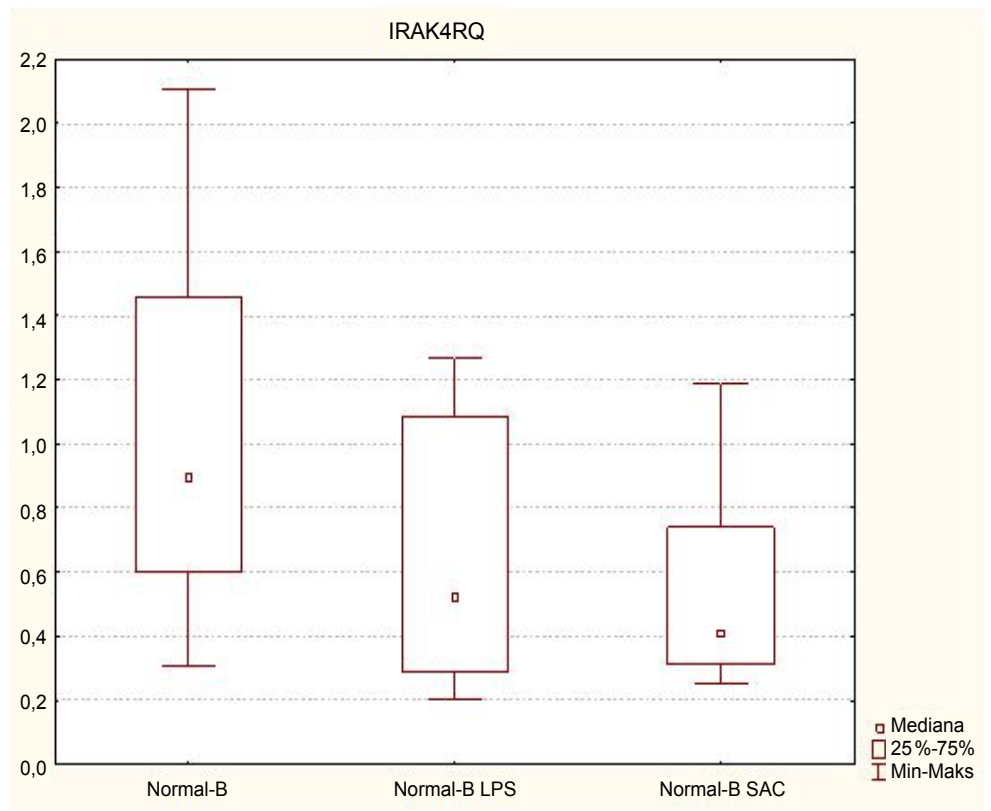

Figure 3: IRAK4 mRNA expression after LPS and SAC stimulation of normal B lymphocytes.

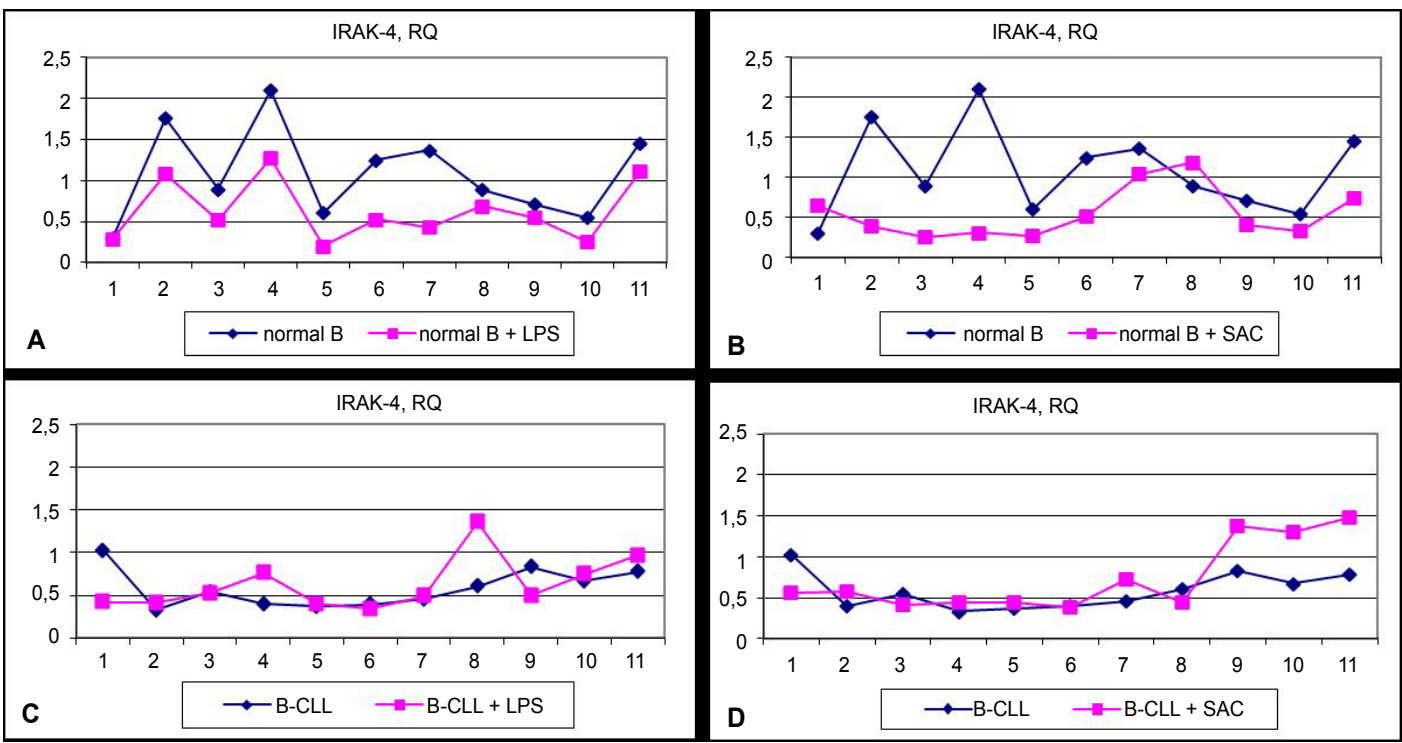

Figure 4: Impact of LPS (A) and SAC (B) stimulation on mRNA IRAK-4 expression in normal CD19+ $B$ lymphocytes in 11 representative cases

[39]. Thus, low mRNA expression of IRAK-4 in unstimulated B-CLL cells could be explained by low expression of TLR4 due to its probable internalization. The types of the ligands that stimulate TLRs on B-CLL cells in peripheral blood, resulting in significantly lower IRAK- 4 mRNA expression comparing to the normal lymphocytes, remain undefined.

Assuming the existence of permanently stimulating ligand in CLL, it can also be presumed that the obtained result is a consequence of TLR tolerance.

The hypothesis of tolerance might be considered when comparing IRAK-4 mRNA expression in normal, unstimulated and LPS/SAC stimulated lymphocytes. Both the LPS and SAC treatment led to significant IRAK-4 down-regulation $(0.90$ vs 0.53 vs $0.40 ; p=0.03$ vs $\mathrm{p}=0.013$ ) (Figure 3 ). The effects of LPS and SAC stimulation of $\mathrm{B}$ lymphocytes in eleven representative cases are presented on the graph (Figure 4A and 4B). IRAK-4 mRNA level reflects its expression at the protein level in normal lymphocytes. Representative results of the first three (Figure 4A and 4B) healthy donors tested are presented on (Figure 5C).

Such a relation was not demonstrated in CLL cells. The changes in IRAK-4 mRNA expression were not statistically significant ( 0,54 vs 0,50 vs 0,$55 ; \mathrm{p}=0.682142$ vs $\mathrm{p}=0.294036$ ). After LPS or SAC stimulation of B-CLL cells, generally there were no difference in IRAK-4 mRNA 


\section{LPS SAC 2. LPS SAC 3. LPS SAC}

A.

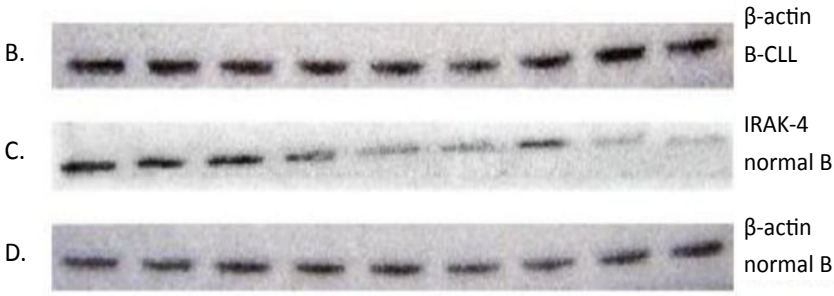

Figure 5: Representative Western blots of IRAK-4 protein expression in normal and B-CLL lymphocytes. Signals were normalized using $\beta$-actin signal. Lines 1, 2, 3 - unstimulated lymphocytes; lines LPS - LPS-stimulated lymphocytes; lines SAC - SAC-stimulated lymphocytes.

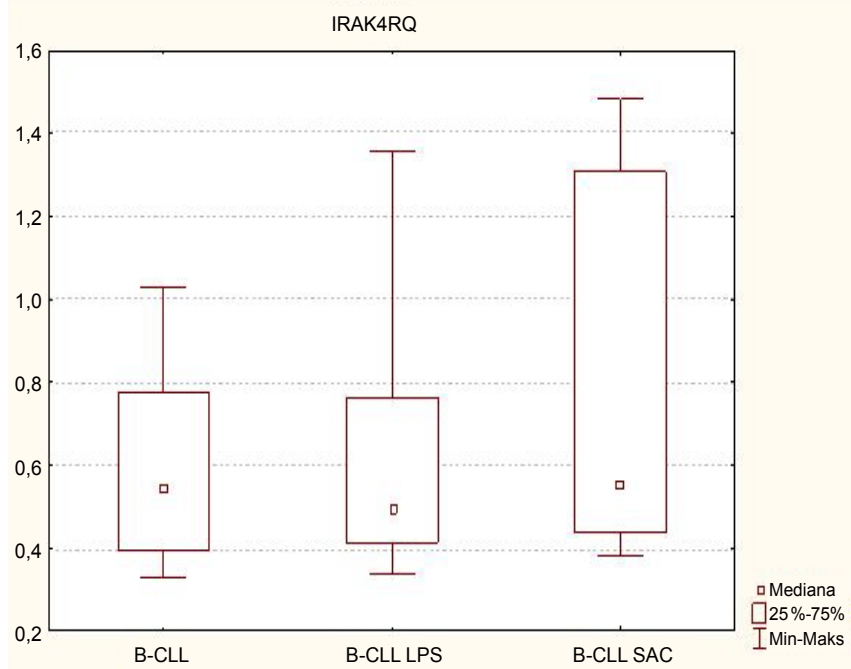

Figure 6: IRAK4 mRNA expression after LPS and SAC stimulation of CLL lymphocytes.

and protein expression. However, in some cases, IRAK-4 mRNA and protein increased expression was observed upon stimulation (Figure $5 \mathrm{~A}$ patient no 2). The increase was shown in 4 and 12 cases at mRNA level, respectively after LPS and SAC stimulation in CLL (Figure 6). Representative results of the first three (Figure 4C and 4D) CLL patients, are presented on (Figure 5A). We observed the reduction of IRAK-4 expression after LPS only in two out of 35 cases. After SAC stimulation only three cases showed IRAK-4 mRNA and protein downregulation (Figure 4C and 4D).

Analysis of IRAK-4 mRNA expression, before and after LPS and SAC stimulation confirmed significant heterogeneity of the CLL which is a well-known feature of that disease. Leukemic B-cell response to LPS and SAC stimulation did not depend on the disease stage according to Rai.

IRAK-4 mRNA expression in normal B lymphocytes seems to be consistent with the one observed in model macrophage lines [47]. Studying the kinetics of IRAK-4 expression, the authors found that 2 hour LPS stimulation resulted in 25\% decrease of IRAK- 4 mRNA expression and after further 8 hours of LPS treatment it went down up to $\sim 80 \%$. It kept being reduced down for the next 24 hour of stimulation. The authors observed a comparable decrease in IRAK4 expression in macrophages stimulated with $\mathrm{CpG}$. These findings suggest that reduction of IRAK-4 expression in normal cells, both after LPS, unmethylated CpG dinucleotides, or as in the presented study, even after SAC, may contribute to the induction of tolerance, regardless of which receptor is induced. LPS is the ligand for TLR4, SAC for TLR2 and CpG for TLR9.

IRAK-4 kinase is absolutely necessary for TIR signaling and is essential for protective immunity against certain bacterial infections. People with IRAK-4 deficiency appear to be particularly susceptible to infections caused by Streptococcus pneumoniae and Staphylococcus aureus which is accompanied by minimal inflammatory response. Lack of IRAK4 causes severe immunodeficiency [48]. IRAK4 defect was first described by Picard et al. in three unrelated children with pyogenic bacterial infections [49]. The cause of the disease was inherited recessive mutations in the IRAK4 (12q12) and the lack of IRAK-4 protein. The impairment of adaptive cellular and humoral response in CLL results in a characteristic pyogenic bacterial infections in these patients. This may indicate a failure of the TIR-IRAK signaling pathway function, resulting in a lack of specific protection against pyogenic bacteria. Interestingly, patients deficient in IRAK-4 are resistant to most ubiquitous microorganisms, including viruses, fungi and parasites, and numerous other bacteria. This is due to the fact that other signaling pathways are activated and other adaptor proteins and kinases are involved in control and prevention from infections by microorganisms other than pyogenic bacteria [50].

The mutation of IRAK-4 has not been yet described in CLL. In our study the Western blot analysis showed protein expression in each of the studied cases, despite of the low mRNA expression level. Interestingly, the decreased expression of IRAK4 at mRNA level was not accompanied by low IRAK4 protein level as we observed in Western blot study. Since there is no any functional study we can assume that IRAK4 protein accumulates in the leukemic cell due to yet unknown molecular mechanism. Medvedev at al. identified the point mutations in IRAK4 resulting in a truncated kinase domain [17]. There exist possibility these mutations lead to IRAK4 protein accumulation that fail to respond to LPS and SAC stimulation in neoplastic cell.

The underlying cause of aberrant IRAK-4 expression in B-CLL may be inappropriate phosphorylation/kinase activity or IRAK-4 mutation. Our earlier observations, concerning the expression of TIRAP adaptor protein that is phosphorylated by IRAK- 4 seem to confirm this hypothesis [51]. We have noticed decrease in TIRAP protein expression after LPS stimulation in normal lymphocytes in contrast to CLL cells. In 2010, Dunne et al. showed similar results suggesting that TIRAP, physiologically, is subjected to phosphorylation, ubiquitination and finally degradation upon LPS stimulation. IRAK1 and IRAK-4 kinase inhibitors effectively inhibited the TIRAP ubiquitination and degradation [52]. Lack of differences in TIRAP expression in CLL after LPS and SAC stimulation could therefore confirm our supposition about impaired function of IRAK4 and/or IRAK1 kinase in CLL. What kind of factors can lead to deregulation of IRAK-4 function in CLL and whether they affect TLR tolerance, remains unknown at the moment.

The latest reports indicate the participation of miRNAs in TLR receptor signaling and endotoxic tolerance regulation [53]. It was shown that miR-146a establishes and maintains endotoxic tolerance by acting on key signaling pathway components such as MyD88, IRAK1, 
Citation: Antosz H, Sajewicz J, Marzec-Kotarska B, Choroszynska D, Hus I, et al. (2014) Distinct IRAK4 Expression in Normal and B-CLL Lymphocytes. J Cytol Histol 5: 228. doi:10.4172/2157-7099.1000228

IRAK2, TRAF6 [tumor-necrosis factor (TNF) receptor-associated factor 6]. Navarro and Lieberman [54] agreed that TIRAP mRNA is target for miR-145.

Recent reports showed also that stimulation of TLR ligands can alter the expression of miRNA affecting the function of these molecules [5558]. Many researchers compete in ligand/ligands searching. Discovery of the proper ligand/ligands could be helpful in understanding some of the aspects of CLL pathogenesis.

In our study we have shown aberrant expression of IRAK4 on mRNA and protein level in $\mathrm{CD}^{+} \mathrm{CD}^{+} 9^{+}$leukemic B lymphocytes. IRAK-4 mRNA expression was lower in leukemic comparing to the normal lymphocytes. We also found distinct dynamics between leukemic and normal cell in IRAK4 expression upon LPS and SAC stimulation.

Interestingly no trend or significant differences in IRAK-4 expression in leukemic lymphocytes after LPS and SAC stimulation may imply the presence of alleged defect of immune tolerance in CLL. The observed phenomenon may provide the basis for debate over the efficiency of signal transmission mediated by TLRs in B-CLL.

Based on our previous results and the present one, we can speculate that the expression of certain adapter proteins and IRAK4 kinase in $\mathrm{B}$-CLL is different from the expression of their counterparts in normal $B$ cells [46,51]. Whether this defect is the cause of immune disorders in patients with B-CLL remains to be proven.

\section{Acknowledgment}

This project was supported by KBN grant NN402 440639. The equipment used was purchased with funds from 'The equipment of Innovative laboratories doing research on new medicines used in the therapy of civilization and neoplastic diseases' Project, part of the Development of Eastern Poland Operational Program 2007-2013, Priority Axis and Modern Economy, Operations I.3 Innovation Promotion.

\section{References}

1. Lee MS, Kim YJ (2007) Signaling pathways downstream of pattern-recognition receptors and their cross talk. Annu Rev Biochem 76: 447-480.

2. Litman GW, Cooper MD (2007) Why study the evolution of immunity? Nat Immunol 8: 547-548.

3. Rolff J (2007) Why did the acquired immune system of vertebrates evolve? Dev Comp Immunol 31: 476-482.

4. Barr TA, Brown S, Ryan G, Zhao J, Gray D (2007) TLR-mediated stimulation of APC: Distinct cytokine responses of B cells and dendritic cells. Eur J Immunol 37: 3040-3053

5. Lund FE (2008) Cytokine-producing B lymphocytes-key regulators of immunity. Curr Opin Immunol 20: 332-338.

6. O'Neill LA, Bowie AG (2007) The family of five: TIR-domain-containing adaptors in Toll-like receptor signalling. Nat Rev Immunol 7: 353-364

7. Medzhitov R (2009) Approaching the asymptote: 20 years later. Immunity 30 766-775

8. Gay NJ1, Gangloff M (2007) Structure and function of Toll receptors and their ligands. Annu Rev Biochem 76: 141-165.

9. Kawai T, Akira S (2007) TLR signaling. Semin Immunol 19: 24-32.

10. Miyake K (2007) Innate immune sensing of pathogens and danger signals by cell surface Toll-like receptors. Semin Immunol 19: 3-10.

11. Kumar H, Kawai T, Akira S (2011) Pathogen recognition by the innate immune system. Int Rev Immunol 30: 16-34.

12. Gottipati S, Rao NL, Fung-Leung WP (2008) IRAK1: a critical signaling mediator of innate immunity. Cell Signal 20: 269-276.
13. Li S, Strelow A Fontana EJ, Wesche $\mathrm{H}$ (2002) IRAK-4: a novel member of the IRAK family with the properties of an IRAK-kinase. Proc Natl Acad Sci U S A 99: 5567-5572

14. Suzuki N, Suzuki S, Yeh WC (2002) IRAK-4 as the central TIR signaling mediator in innate immunity. Trends Immunol 23: 503-506.

15. Janssens S, Beyaert R (2003) Functional diversity and regulation of different interleukin-1 receptor-associated kinase (IRAK) family members. Mol Cell 11 293-302.

16. Suzuki N, Suzuki S, Duncan GS, Millar DG, Wada T, et al. (2002) Severe impairment of interleukin-1 and Toll-like receptor signalling in mice lacking IRAK-4. Nature 416: 750-756

17. Medvedev AE, Lentschat A, Kuhns DB, Blanco JC, Salkowski C, et al. (2003) Distinct mutations in IRAK-4 confer hyporesponsiveness to lipopolysaccharide and interleukin-1 in a patient with recurrent bacterial infections. J Exp Med 198: 521-531.

18. Hamblin TJ, Oscier DG, Young BJ (1986) Autoimmunity in chronic lymphocytic leukaemia. J Clin Pathol 39: 713-716.

19. Vuillier F, Dumas G, Magnac C, Prevost MC, Lalanne Al, et al. (2005) Lower levels of surface B-cell-receptor expression in chronic lymphocytic leukemia are associated with glycosylation and folding defects of the mu and CD79a chains. Blood 105: 2933-2940.

20. Cascalho M, Platt JL (2007) Novel functions of B cells. Crit Rev Immunol 27: 141-151.

21. Ruprecht CR, Lanzavecchia A (2006) Toll-like receptor stimulation as a third signal required for activation of human naive B cells. Eur $\mathrm{J} \mathrm{Immunol} \mathrm{36:} \mathrm{810-}$ 816.

22. Payelle-Brogard B, Magnac C, Alcover A, Roux P, Dighiero G (2002) Defective assembly of the B-cell receptor chains accounts for its low expression in B-chronic lymphocytic leukaemia. Br J Haematol 118: 976-985.

23. Gordon MS, Kato RM, Lansigan F, Thompson AA, Wall R, et al. (2000) Aberrant $B$ cell receptor signaling from B29 (Igbeta, CD79b) gene mutations of chronic lymphocytic leukemia B cells. Proc Natl Acad Sci U S A 97: 5504-5509.

24. Hall AM, Vickers MA, McLeod E, Barker RN (2005) Rh autoantigen presentation to helper T cells in chronic lymphocytic leukemia by malignant B cells. Blood 105: $2007-2015$

25. Görgün G, Holderried TA, Zahrieh D, Neuberg D, Gribben JG (2005) Chronic lymphocytic leukemia cells induce changes in gene expression of CD4 and CD8 T cells. J Clin Invest 115: 1797-1805.

26. Ramsay AG, Gribben JG (2009) Immune dysfunction in chronic lymphocytic leukemia $\mathrm{T}$ cells and lenalidomide as an immunomodulatory drug. Haematologica 94: 1198-1202.

27. Rebmann V, Nückel H, Dührsen U, Grosse-Wilde H (2007) HLA-G in B-chronic lymphocytic leukaemia: clinical relevance and functional implications. Semin Cancer Biol 17: 430-435.

28. Riches JC, Ramsay AG, Gribben JG (2010) T-cell function in chronic lymphocytic leukaemia. Semin Cancer Biol 20: 431-438.

29. Sampalo A, Brieva JA (2002) Humoral immunodeficiency in chronic lymphocytic leukemia: role of CD95/CD95L in tumoral damage and escape. Leuk Lymphoma 43: 881-884

30. Maki G, Hayes GM, Naji A, Tyler T, Carosella ED, et al. (2008) NK resistance of tumor cells from multiple myeloma and chronic lymphocytic leukemia patients: implication of HLA-G. Leukemia 22: 998-1006.

31. Shvidel L, Vorst E, Berrebi A (1998) Complement values in B chronic lymphocytic leukemia: prognostic significance and correlation with cell maturation stage. Leukemia 12: 635-636.

32. Hallek M, Cheson BD, Catovsky D, Caligaris-Cappio F, Dighiero G, et al. (2008) Guidelines for the diagnosis and treatment of chronic lymphocytic leukemia: a report from the International Workshop on Chronic Lymphocytic Leukemia updating the National Cancer Institute-Working Group 1996 guidelines. International Workshop on Chronic Lymphocytic Leukemia. Blood 111: 54465456.

33. Rai KR, Sawitsky A, Cronkite EP, Chanana AD, Levy RN, et al. (1975) Clinica staging of chronic lymphocytic leukemia. Blood 46: 219-234.

34. Böyum A (1968) Isolation of mononuclear cells and granulocytes from human blood. Isolation of monuclear cells by one centrifugation, and of granulocytes by combining centrifugation and sedimentation at $1 \mathrm{~g}$. Scand J Clin Lab Invest Suppl 97: 77-89. 
Citation: Antosz H, Sajewicz J, Marzec-Kotarska B, Choroszynska D, Hus I, et al. (2014) Distinct IRAK4 Expression in Normal and B-CLL Lymphocytes. J Cytol Histol 5: 228. doi:10.4172/2157-7099.1000228

35. Chomczynski P, Sacchi N (1987) Single-step method of RNA isolation by acid guanidinium thiocyanate-phenol-chloroform extraction. Anal Biochem 162: 156-159.

36. Poovassery JS, Vanden Bush TJ, Bishop GA (2009) Antigen receptor signals rescue B cells from TLR tolerance. J Immunol 183: 2974-2983.

37. Kawagoe T, Sato S, Jung A, Yamamoto M, Matsui K, et al. (2007) Essential role of IRAK-4 protein and its kinase activity in Toll-like receptor-mediated immune responses but not in TCR signaling. J Exp Med 204: 1013-1024.

38. Hatao F, Muroi M, Hiki N, Ogawa T, Mimura Y, et al. (2004) Prolonged Toll-like receptor stimulation leads to down-regulation of IRAK-4 protein. J Leukoc Bio 76: 904-908.

39. Chiorazzi N, Rai KR, Ferrarini M (2005) Chronic lymphocytic leukemia. N Engl J Med 352: 804-815.

40. Pasare C, Medzhitov R (2004) Toll-like receptors: linking innate and adaptive immunity. Microbes Infect 6: 1382-1387.

41. Cavaillon JM, Adib-Conquy M (2006) Bench-to-bedside review: endotoxin tolerance as a model of leukocyte reprogramming in sepsis. Crit Care 10: 233.

42. Nomura F, Akashi S, Sakao Y, Sato S, Kawai T, et al. (2000) Cutting edge: endotoxin tolerance in mouse peritoneal macrophages correlates with downregulation of surface toll-like receptor 4 expression. J Immunol 164: 3476-3479.

43. West MA, Heagy W (2002) Endotoxin tolerance: a review. Crit Care Med 30: S64-S73.

44. Haxhinasto SA, Bishop GA (2004) Synergistic B cell activation by CD40 and the $B$ cell antigen receptor: role of $B$ lymphocyte antigen receptor-mediated kinase activation and tumor necrosis factor receptor-associated factor regulation. $J$ Biol Chem 279: 2575-2582

45. Liew FY, Xu D, Brint EK, O'Neill LA (2005) Negative regulation of toll-like receptor-mediated immune responses. Nat Rev Immunol 5: 446-458.

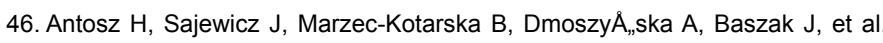
(2012) TLR2 may influence the behavior of the malignant clone in B-CLL. Blood Cells Mol Dis 49: 32-40.

47. De Nardo D, Nguyen T, Hamilton JA, Scholz GM (2009) Down-regulation of IRAK-4 is a component of LPS- and CpG DNA-induced tolerance in macrophages. Cell Signal 21: 246-252.
48. Ku CL, von Bernuth H, Picard C, Zhang SY, Chang HH, et al. (2007) Selective predisposition to bacterial infections in IRAK-4-deficient children: IRAK-4dependent TLRs are otherwise redundant in protective immunity. J Exp Med 204: $2407-2422$

49. Picard C, Puel A, Bonnet M, Ku CL, Bustamante J, et al. (2003) Pyogenic bacterial infections in humans with IRAK-4 deficiency. Science 299: 2076-2079.

50. Yamamoto M, Sato S, Mori K, Hoshino K, Takeuchi O, et al. (2002) Cutting edge: a novel Toll/IL-1 receptor domain-containing adapter that preferentially activates the IFN-beta promoter in the Toll-like receptor signaling. J Immunol 169: 6668-6672.

51. Antosz H, Sajewicz J, Marzec-Kotarska B, DmoszyÅ,ska A, Baszak J, et al (2013) Aberrant TIRAP and MyD88 expression in B-cell chronic lymphocytic leukemia. Blood Cells Mol Dis 51: 48-55.

52. Dunne A, Carpenter S, Brikos C, Gray P, Strelow A, et al. (2010) IRAK1 and IRAK4 promote phosphorylation, ubiquitination, and degradation of MyD88 adaptor-like (Mal). J Biol Chem 285: 18276-18282.

53. Nahid MA, Satoh M, Chan EK (2011) MicroRNA in TLR signaling and endotoxin tolerance. Cell Mol Immunol 8: 388-403.

54. Navarro F, Lieberman J (2010) Small RNAs guide hematopoietic cell differentiation and function. J Immunol 184: 5939-5947.

55. Nahid MA, Pauley KM, Satoh M, Chan EK (2009) miR-146a is critical fo endotoxin-induced tolerance: Implication in innate immunity. J Biol Chem 284 34590-34599.

56. Nahid MA, Satoh M, Chan EK (2011) Mechanistic role of microRNA-146a in endotoxin-induced differential cross-regulation of TLR signaling. J Immunol 186: $1723-1734$

57. Nahid MA, Rivera M, Lucas A, Chan EK, Kesavalu L (2011c) Polymicrobia infection with periodontal pathogens specifically enhances microRNA miR146a in ApoE-/- mice during experimental periodontal disease. Infect Immun 79: 1597-1605.

58. Taganov KD, Boldin MP, Chang KJ, Baltimore D (2006) NF-kappaB-dependent induction of microRNA miR-146, an inhibitor targeted to signaling proteins of innate immune responses. Proc Natl Acad Sci U S A 103: 12481-12486. 